\title{
Prevalence of severe fever with thrombocytopenia syndrome virus in animals in Henan Province, China
}

Xue-Yong Huang ${ }^{1,2+}$, Yan-Hua Du ${ }^{1,2+}$, Hai-Feng Wang ${ }^{1+}$, Ai-Guo You', Yi Li ${ }^{1,2}$, Jia Su', Yi-Fei Nie', Hong-Xia Ma, and Bian-Li Xu ${ }^{1,2^{*}}$ (D)

\begin{abstract}
Severe fever with thrombocytopenia syndrome (SFTS) is an emerging infectious disease caused by severe fever with thrombocytopenia syndrome virus (SFTSV). SFTSV has been found in humans, ticks and animals, and SFTS has high mortality and increasing prevalence in East Asia. In the study, the samples (heart, liver, lung, kidney, spleen, brain tissue and serum) were collected from 374 domestic animals and 241 wild animals in Pingqiao District and Xinxian County of Xinyang in Henan Province, China. 275 (44.72\%, 275/615) animals were positive for anti-SFTSV antibodies, the anti-SFTSV antibodies positive ratios of domestic and wild animals were $43.58 \%(163 / 374)$ and $46.47 \%(112 / 241)$, respectively. There was no significant difference in domestic and wild animals, but significant differences were detected among different species of animals $\left(X^{2}=112.59, P<0.0001\right)$. Among 615 animals, 105 $(17.07 \%, 105 / 615)$ animals were positive for SFTSV RNA, and only one SFTSV strain was isolated from heart tissue of a yellow weasel. The phylogenetic analysis shows that the sequence from animals belonged to the same group with viral sequences obtained from humans. The animals maybe play a reservoir host in maintaining the life cycle of SFTSV in nature.
\end{abstract}

Keywords: Severe fever with thrombocytopenia syndrome virus, Epidemiological investigation, Animal, Reservoir host

\section{Multilingual abstracts}

Please see Additional file 1 for translation of the abstract into the five official working languages of the United Nations.

\section{Background}

Severe fever with thrombocytopenia syndrome (SFTS) is an emerging hemorrhagic fever and its pathogen is severe fever with thrombocytopenia syndrome virus (SFTSV). The disease has major clinical presentations that include fever, thrombocytopenia, leukocytopenia, gastrointestinal symptoms, neurological symptoms and a bleeding tendency, as well as less specific clinical manifestations [1]. The disease is widely expanding at global

\footnotetext{
* Correspondence: bianlixu@163.com

${ }^{+}$Xue-Yong Huang, Yan-Hua Du and Hai-Feng Wang contributed equally to this work.

${ }^{1}$ Henan Center for Disease Control and Prevention, Zhengzhou, China

${ }^{2}$ Henan Key Laboratory of Pathogenic Microorganisms, Zhengzhou, China
}

level. Between 2011 and 2014, 5352 suspected, probable and lab-confirmed cases of SFTS were reported in 23 provinces of China. Henan, Shandong, Hubei, Anhui, Liaoning, Zhejiang and Jiangsu reported $99.3 \%$ of those lab-confirmed cases [2-4]. SFTS cases had been reported in Japan and Republic of Korea. In Japan, 163 patients with SFTS were confirmed from the autumn of 2012 to October 2015. The number of SFTS cases reported in Republic of Korea had also increased in recent years, and were 36 (2013), 55 (2014) and 79 (2015) [5, 6].

SFTSV has a wide host range and infects in some animal species. The pooled seroprevalence of anti-SFTSV antibodies was $45.70 \%$ in goats and sheep, $36.70 \%$ in cattle, $29.50 \%$ in dogs, $9.60 \%$ in chickens, $3.20 \%$ in rodents, and $3.20 \%$ in pigs. SFTSV RNA was also detected in blood samples from several animal species, with a carriage rate varying from 0.23 to $26.31 \%$, The highest carriage rate of SFTSV RNA was detected in cattle (up to $26.31 \%$ ), followed by cats (17.46\%), goats 
(9.10\%), and rodents $(8.44 \%)$, but there is no evidence that the virus can cause disease in animals $[7,8]$.

It is known that SFTSV can be detected in humans, various domestic animals and ticks. Although researchers had demonstrated in the laboratory that the SFTSV can be passed transstadially in the developmental stages of the ticks which can be as a host and reservoir of infection to spread SFTSV by biting humans and animals. But the prevalence of SFTSV infection among ticks collected from vegetation was quite low, suggesting that ticks alone may not be sufficient to maintain the virus in nature, so SFTSV must rely on other animals as storage hosts to circulate in nature [9]. This study was to explore the animal host reservoir range of SFTSV, and to elucidate SFTSV ecology in nature by detecting the anti-SFTSV antibodies and SFTSV RNA positive ratio of domestic animals and wild animals in the SFTS endemic region.

\section{Methods}

\section{Research area and sample collection}

The study was conducted in Pingqiao District and Xinxian County of Xinyang City in Henan Province, China, where had the most reported SFTS cases and was the most severe affected areas in China [10, 11]. From May 1, 2016 to April 30, 2018, the samples (serum, heart, liver, lung, kidney, spleen and brain tissue) were collected from 374 domestic animals (including 48 cattle, 76 sheep, 44 dogs, 63 pigs, 82 chickens and 61 ducks) and 241 wild animals (including 45 yellow weasels, 73 hares, 52 wild mice, 15 hedgehogs, five squirrels, three wild boars, four badgers, 23 rock pigeons, 14 pheasants and seven turtledoves) (Table 1). All samples were transported under refrigeration to Henan Center for Disease Control and Prevention (Henan CDC) and kept in a freezer at $-80{ }^{\circ} \mathrm{C}$.

\section{Enzyme-linked immunosorbent assays (ELISA)}

Total SFTSV antibodies (including IgG and IgM) were detected in serum samples using a double-antigen sandwich ELISA kit (Xinlianxin Biomedical Technology CO., LTD, Wuxi, Jiangsu, China) according to the manufacturer's protocol. For this ELISA kit, $100 \mu \mathrm{l}$ of serum samples were diluted to $1: 5$, and positive and negative controls were added. Samples were incubated at $37^{\circ} \mathrm{C}$ for $30 \mathrm{~min}$, washed with phosphate-buffered saline (PBS), and $100 \mu \mathrm{l}$ of horseradish peroxidase-conjugated nucleoprotein was added. Plates were developed by using a substrate solution after samples were incubated and washed. The chromogenic reaction was stopped by sulfuric acid, and absorbance was identified at $450 \mathrm{~nm}$. The test results were determined to be valid if the criteria for the positive and the negative controls were fulfilled [12, 13].
Real-time reverse transcription polymerase chain reaction (RT-PCR) detection

The animal tissue samples $\left(0.5-1 \mathrm{~cm}^{3}\right)$ were ground by Tissuelyser (Mixer Mill MM 400, Retsch GmbH, Haan, Germany). Total RNA was extracted from serum samples and tissue-grinding solution using a QIAamp viral RNA mini Kit (Qiagen, Hilden, Germany), according to the manufacturer's instructions. RNA was eluted in a final volume of $60 \mu \mathrm{l}$ elution buffer and used immediately or stored at $-80^{\circ} \mathrm{C}$. RNA from each sample was examined by real-time RT-PCR Kit (Beijing BGI-GBI Biotech Co., Ltd. Beijing, China). The conditions for real-time RT-PCR reaction were as follows: $50^{\circ} \mathrm{C}$ for 30 min, $95^{\circ} \mathrm{C}$ for $15 \mathrm{~min}, 40$ cycles of $95^{\circ} \mathrm{C}$ for $15 \mathrm{~s}$, and $60^{\circ} \mathrm{C}$ for $45 \mathrm{~s}$. Criteria for a positive result was cycle number $(\mathrm{Ct})<38$, according to the instructions from the real-time RT-PCR Kit.

\section{Virus isolation and sequencing}

All positive samples (serum, tissue-grinding solution) for SFTSV RNA were used to inoculate Vero E6 cells. After processing, $100 \mu \mathrm{l}$ of samples was inoculated into a 25 $\mathrm{cm}^{2}$ flask containing Vero E6 cell monolayers. Tubes were incubated at $37^{\circ} \mathrm{C}$ for 14 days and changed media after 7 days. All cultures were monitored daily for the cytopathic effect (CPE). Each sample underwent at least three cell culture passages in Vero E6 cells before being considered negative [14]. Both virus-infected cells and negative control cells were examined for SFTSV by realtime RT-PCR at each passage. The whole genome sequences of SFTSV were amplified using primers described in previous studies by RT-PCR [15]. The RTPCR products were sent to Sangon Biotech Co., Ltd. (Shanghai, China) for DNA sequencing with an automated ABI 3730 DNA sequencer (Applied Biosystems, Foster City, CA, USA).

\section{Genome alignments and phylogenetic analysis}

The genomes of SFTSV isolates were compiled using the SeqMan program in the Lasergene software package (DNASTAR, Version 2.0, Madison, WI, USA). The percentage similarities of nucleotide identity were calculated using the Clustalx software (Version 2.0, European Bioinformatics Institute [EMBLEBI], Cambridge, UK). Molecular phylogenetic analysis was conducted by using the maximum likelihood (ML) method based on the Kimura 2-parameter model in the molecular evolutionary genetics analysis (MEGA) 5 software (available at: http:// mega.software.informer.com/5.0/) [16]. The tree with the highest log likelihood was shown, and the percentage of trees in which the associated taxa clustered together was shown next to the branches [11]. The available nucleotide sequences of genome segments of SFTSV isolates from GenBank were analysed, together with the newly 
Table 1 The results of SFTSV RNA and antibodies in specimens of animals by real-time RT-PCR or ELISA assay

\begin{tabular}{|c|c|c|c|c|c|c|c|c|}
\hline $\begin{array}{l}\text { Animal } \\
\text { species }\end{array}$ & $\begin{array}{l}\text { Number of Animal } \\
\text { (Positive rate \%) }\end{array}$ & $\begin{array}{l}\text { Heart } \\
\text { (Positive rate \%) }\end{array}$ & $\begin{array}{l}\text { Liver } \\
\text { (Positive rate \%) }\end{array}$ & $\begin{array}{l}\text { Spleen } \\
\text { (Positive rate \%) }\end{array}$ & $\begin{array}{l}\text { Lungs } \\
\text { (Positive rate \%) }\end{array}$ & $\begin{array}{l}\text { Kidney } \\
\text { (Positive rate \%) }\end{array}$ & \multicolumn{2}{|c|}{$\begin{array}{l}\text { Serum } \\
\text { (Positive rate \%) }\end{array}$} \\
\hline $\begin{array}{l}\text { Domestic } \\
\text { animals }\end{array}$ & & & & & & & $\begin{array}{l}\text { SFTSV } \\
\text { RNA }\end{array}$ & $\begin{array}{l}\text { SFTSV } \\
\text { antibodies }\end{array}$ \\
\hline Cattles & 48 (18.75\%) & $1(2.08 \%)$ & $2(4.17 \%)$ & $5(10.42 \%)$ & $3(6.25 \%)$ & $3(6.25 \%)$ & $\begin{array}{l}1 \\
(2.08 \%)\end{array}$ & 47 (97.92\%) \\
\hline Sheep & 76 (15.79\%) & $3(3.95 \%)$ & $4(5.26 \%)$ & 7 (9.21\%) & $2(2.63 \%)$ & $4(5.26 \%)$ & 0 & $53(69.74 \%)$ \\
\hline Dogs & 44 (13.64\%) & 0 & $2(4.55 \%)$ & $3(6.82 \%)$ & $1(2.27 \%)$ & $1(2.27 \%)$ & 0 & 30 (68.18\%) \\
\hline Pigs & 63 (11.11\%) & $3(4.76 \%)$ & $1(1.59 \%)$ & $4(6.35 \%)$ & $1(1.59 \%)$ & 0 & 0 & $2(3.17 \%)$ \\
\hline Chickens & 82 (19.51\%) & 9 (10.98\%) & 7 (8.54\%) & $4(4.82 \%)$ & 10 (12.20\%) & 0 & 0 & 19 (23.17\%) \\
\hline Ducks & $61(14.75 \%)$ & $3(4.92 \%)$ & $5(8.20 \%)$ & $2(3.28 \%)$ & $5(8.20 \%)$ & $1(1.64 \%)$ & 0 & $12(19.67 \%)$ \\
\hline Total & $374(15.76 \%)$ & 19 (5.08\%) & $21(5.61 \%)$ & $25(6.68 \%)$ & 22 (5.88\%) & 9 (2.41\%) & $\begin{array}{l}1 \\
(0.23 \%)\end{array}$ & $163(43.58 \%)$ \\
\hline \multicolumn{9}{|l|}{ Wild animals } \\
\hline $\begin{array}{l}\text { Yellow } \\
\text { weasels }\end{array}$ & 45 (37.78\%) & $2(4.44 \%)$ & 4 (8.89\%) & $11(24.44 \%)$ & $3(6.67 \%)$ & $6(13.33 \%)$ & $\begin{array}{l}1 \\
(2.22 \%)\end{array}$ & 41 (91.11\%) \\
\hline Hares & 73 (21.92\%) & $3(4.11 \%)$ & $1(1.37 \%)$ & $13(17.81 \%)$ & $3(4.11 \%)$ & $2(2.74 \%)$ & $\begin{array}{l}2 \\
(2.74 \%)\end{array}$ & 46 (63.01\%) \\
\hline Wild mice & $52(3.85 \%)$ & 0 & $2(3.85 \%)$ & 0 & 0 & 0 & 0 & $4(7.69 \%)$ \\
\hline Hedgehogs & 15 (13.33\%) & 0 & 0 & $2(13.33 \%)$ & 0 & 0 & 0 & $6(40.00 \%)$ \\
\hline Squirrels & 5 & 0 & 0 & 0 & 0 & 0 & 0 & 0 \\
\hline Wild boars & 3 & 0 & 0 & 0 & 0 & 0 & 0 & 0 \\
\hline Badgers & 4 & 0 & 0 & 0 & 0 & 0 & 0 & 0 \\
\hline $\begin{array}{l}\text { Rock } \\
\text { pigeons }\end{array}$ & $23(21.74 \%)$ & $3(13.04 \%)$ & $2(8.70 \%)$ & 0 & $1(4.35 \%)$ & 0 & 0 & $8(34.78 \%)$ \\
\hline Pheasants & 14 (28.57\%) & 0 & $2(14.29 \%)$ & 0 & $3(21.43 \%)$ & 0 & 0 & $6(42.86 \%)$ \\
\hline Turtledoves & 7 & 0 & 0 & 0 & 0 & 0 & 0 & 1 (14.29\%) \\
\hline Total & 241 (19.09\%) & $8(3.32 \%)$ & $11(4.56 \%)$ & $26(10.79 \%)$ & $10(4.15 \%)$ & $8(3.32 \%)$ & $\begin{array}{l}3 \\
(1.24 \%)\end{array}$ & $112(46.47 \%)$ \\
\hline
\end{tabular}

Animal positive rate: at least one sample from one animal was positive for SFTSV RNA by real-time RT-PCR, the samples include heart, liver, spleen, lungs and kidney tissue

Detection methods: the heart, liver, spleen, lungs and kidney tissues were tested by real-time RT-PCR; the serum samples were tested by real-time RT-PCR and ELISA assay

Abbreviations: SFTSV Severe fever with thrombocytopenia syndrome virus, RT-PCR Reverse transcription polymerase chain reaction, ELISA Enzyme-linked immunosorbent assay, RNA Ribonucleic acid

generated genes of SFTSV in this study, and the phylogenetic trees were constructed to understand the evolutionary characterization of SFTSV.

\section{Statistical analysis}

All statistical analyses were performed using SAS (Version 9.13, SAS Institute Inc., Cary, NC, US). Count data was analyzed by $\chi^{2}$ test or Fisher's exact test. A significant difference was considered with a $P$ value less than 0.05 .

\section{Ethical clearance}

The research was approved by the Ethical Committee of Henan CDC (Reference number: 2016-KY-002-02). The collection of wild animals was permitted by Pingqiao District and Xinxian County Forestry Bureau. Animals were captured by hunters, who were supplied with safety protection.

\section{Results}

\section{Anti-SFTSV antibody among animals}

All serum samples were tested for anti-SFTSV total antibodies using an ELISA assay. Two hundred seventy-five animals $(44.72 \%, 275 / 615)$ were positive for anti-SFTSV antibodies; the positive ratios of domestic and wild animals were $43.58 \%(163 / 374)$ and $46.47 \%(112 / 241)$, respectively, there was no significant difference between domestic and wild animals $\left(\chi^{2}=0.1884, P>0.05\right)$, The positive ratio of the mammals $(53.50 \%, 229 / 428)$ was higher than that of birds $(24.60 \%, 46 / 187)\left(\chi^{2}=18.40\right.$, $P<0.0001)$. The higher positivity rate of the antibodies in domestic animals ware cattle $(97.92 \%, 47 / 48)$, sheep 
$(69.74 \%, 53 / 76)$ and dogs $(68.18 \%, 30 / 44)$, the lowest positive rate in domestic animals is pigs $(3.17 \%, 2 / 63)$. In the wild animals, yellow weasels $(91.11 \%, 41 / 45)$ and hares $(63.01 \%, 46 / 73)$ were higher than other animals, there are three animals (squirrels and wild boars and badgers) the positive rates were zero. There were significant differences in different species of animal $\left(\chi^{2}=112.59, P<0.0001\right)$ (Table 1$)$.

\section{Real-time PCR for SFTSV on animal samples}

In 615 animal serum samples, four samples were classified as positive based on real-time RT-PCR Kit criteria (one cattle, one yellow weasel and two hares). Additionally, 105 out of 615 (17.07\%) animals were positive for SFTSV RNA, in which at least one organ was positive according to real-time RT-PCR. The brains were negative for SFTSV RNA in all animals. The positive rate of domestic animals and wild animals were $15.76 \%(59 / 374)$ and $19.09 \%$ (46/241), respectively. There were no significant differences between domestic animals and wild animals $\left(\chi^{2}=0.7994\right.$, $P>0.05)$. There were no significant differences in the positive rates of SFTSV RNA among animal species $\left(\chi^{2}=23.77, P>0.05\right)$, but the positive rate was higher in the domestic cattle $(18.75 \%, 9 / 48)$, chickens $(19.51 \%, 16 / 82)$ and sheep $(15.79 \%, 12 / 76)$, and in the wild animals yellow weasels $(37.78 \%, 17 / 45)$, pheasants $(28.57 \%, 4 / 14)$, hares $(21.92 \%, 16 / 73)$ and rock pigeons $(21.74 \%, 5 / 23)$. There were significant differences in the positive rates among organs of animals $\left(X^{2}=\right.$ 105.70, $P<0.0001)$, the positive rate was the highest in spleen $(8.29 \%, 51 / 615)$, and the lowest in kidney $(2.76 \%, 17 / 615)$ (Table 1).

\section{Sequence analysis of isolates}

One strain SFTSV was isolated and confirmed from heart tissue of a yellow weasel in this study by real-time RT-PCR. The genomes of the SFTSV isolates were sequenced and submitted to GenBank (Accession No. MF574211, MF574212, MF574213). The nucleotide sequences of this SFTSV were aligned using the basic local alignment search tool (BLAST) at the National Centre for Biotechnology Information (NCBI) (https:// blast.ncbi.nlm.nih.gov/Blast.cgi). BLAST results showed that this isolate strain was related closely to known sequences, with 96.64 to $99.91 \%$ nucleotide identity for the complete L segments, 96.15 to $99.67 \%$ nucleotide identity for the complete $M$ segments, and 98.51 to 99.89\% nucleotide identity for the complete $\mathrm{S}$ segments.

Phylogenetic trees were constructed with the sequences of 28 SFTSV strains from GenBank. Based on the alignment of $\mathrm{L}, \mathrm{M}, \mathrm{S}$ segments sequences for phylogenetic analysis, these SFTSV strains were classified into four groups (A, B, C and D). The SFTSV strain from animals belonged to Group A with viral strains obtained from humans in Henan Province (Fig.1).

\section{Discussion}

Serological epidemiology of SFTSV was surveyed among domesticated animals in many previous studies. SFTSV antibody positive rate had a larger difference in the same animal species among different epidemic areas, but sheep, cattle, dogs and chickens had very high positive rate and high levels of SFTSV antibodies [17-20]. The SFTSV antibody positive rate was over $90 \%$ in cattle and $60 \%$ in sheep and dogs in this study. Liu, et al. and Li, et al. had investigated seropositive rate of SFTSV in rodents and hedgehogs by ELISA, and showed SFTSV

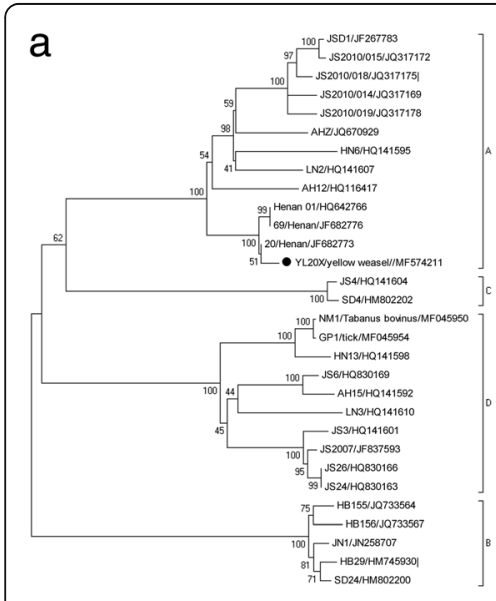

$\longmapsto 0005$

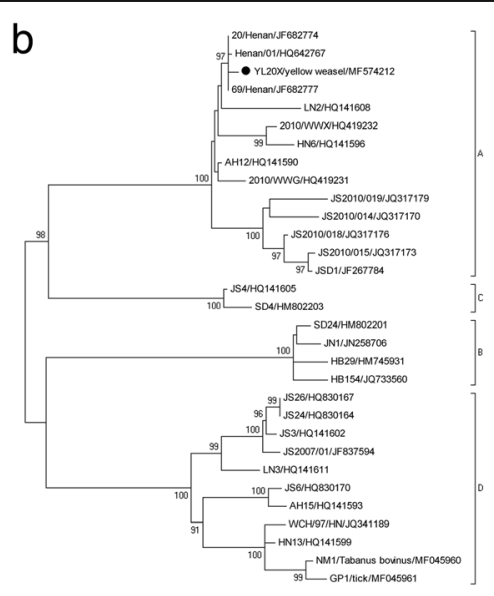

$\longmapsto 0005$

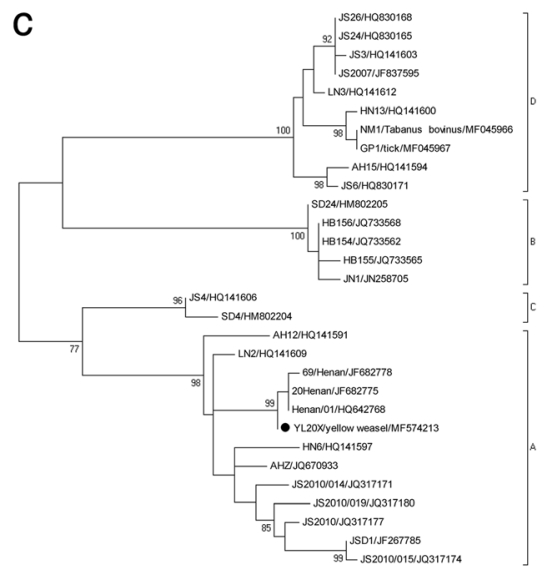

$\longdiv { 0 . 0 0 5 }$

Fig. 1 Phylogenetic analyses of SFTSV based on L, M, S segment sequences. The tree shows the comparison between the SFTSV strains of study and reference strains. The circle symbol represents SFTSV strains isolated from yellow weasel in this study 
antibody positive rate was low in these wild animals $[21,22]$. In this study, the SFTSV antibody positive rate was similar with previous studies in domesticated animals, but was high in wild animals, especially in yellow weasels and hares. The SFTSV antibody positive rate was more than $90 \%$ in yellow weasels and $60 \%$ in hares. The incidence of SFTSV infection was correlated to the life style of the animals. This may be due to the freerange life style of domesticated cattle, goats, dogs and wild yellow weasels, hares, so these animals expose to a greater risk of tick bites than other animals, for example, pigs are usually captivity.

The results of this study showed that SFTSV-carrying rate was $17.07 \%$ among domestic animals and wild animals in epidemic areas in Henan, China, by real-time RT-PCR, and one SFTSV strain was isolated from a yellow weasel. The PCR positive rate of all animals was higher than all previous studies because the collection of sample types was different from them. In this study, the serum, heart, liver, lung, kidney, spleen and brain tissue samples were collected from animals. One organ from an animal was positive by real-time RT-PCR, the animal was judged as carrying SFTSV, but SFTSV RNA was only detected in serum samples from animals in previous studies. A total of 6637 blood samples from 11 animal species were testing for SFTSV RNA in twelve published articles, while the carriage rates of SFTSV RNA ranged from 0.23 to $26.31 \%$ [7] (Additional file 2: Table S1), $2.08 \%$ in cattle, $2.22 \%$ in yellow weasel, $(2.74 \%$ on hare (in this survey, the results were similar with those previous studies. The positive rate of domestic animals and wild animals were no significant differences, and there were no significant differences between animal species. SFTSV RNA was detected in heart, liver, spleen, lungs, kidney from cattle, goats, wild yellow weasels and hares, which were more susceptible to infection and carry SFTSV. The results showed that some animals can carry SFTSV but no any specific clinical signs of illness.

The previous animal experiments showed that newborn mice, mitomycin-treated mice, and type I IFNdeficient mice are available as models for the fatal illness caused by SFTSV infection [23-25]. Immunocompetent adult mice, hamsters, and macaques were not susceptible to SFTSV and were asymptomatic, the level of white blood cell were slightly low among experimental animals and platelet counts at one time point; SFTSV load substantially decreased in blood on day 3 or 4 after inoculation; SFTSV RNA was detected in the spleen, liver, kidney; SFTSV-specific IgM and IgG antibodies were detected in sera [26-29].

Natural infection study showed goats were infected by ticks in the SFTS-endemic region. The goats were viremia over a very short period (less than $24 \mathrm{~h}$ ) after viral infection, soon occupied by a timely mounting antibody response which effectively controlled the infection. The whole cohort did not show any specific clinical signs of illness, and all survived infection $[9,30]$. The animals were infected in the laboratory or SFTSendemic region, and viremia persisted for a short period, but SFTSV antibody can last for a long time, so detection results of antibody and RNA were greatly different in blood of animals with SFTSV infection. The domestic animals and wild animals may be intermediate animal hosts during SFTSV amplification in endemic area.

This study has two limitations. First, animal selection lacked uniformity in number, especially some wild animals were lesser and captured difficultly in nature. Second, animal species can't be randomly selected to capture.

\section{Conclusions}

The most animals were infected by SFTSV and some carry SFTSV in epidemic areas in China. $44.72 \%$ animals were positive for anti-SFTSV antibodies and $17.07 \%$ animals were positive for SFTSV RNA in Xinyang in Henan Province. The animals maybe play a reservoir host in maintaining the life cycle of SFTSV in nature.

\section{Additional files}

Additional file 1: Multilingual abstracts in the five official working languages of the United Nations. (PDF $402 \mathrm{~kb}$ )

Additional file 2: Table S1. SFTSV RNA positivity as detected in the different animal species from published articles. (DOC $37 \mathrm{~kb}$ )

\section{Abbreviations}

CDC: Center for Disease Control and Prevention; CPE: Cytopathic effect; ELISA: Enzyme-linked immunosorbent assay; ML: Maximum likelihood; PBS: Phosphate-buffered saline; RNA: Ribonucleic acid; RT-PCR: Reverse transcription polymerase chain reaction; SFTS: Severe fever with thrombocytopenia syndrome; SFTSV: Severe fever with thrombocytopenia syndrome virus

\section{Acknowledgements}

Not applicable.

\section{Authors' contributions}

$X Y H, B L X$ contributed to study design, drafting of the manuscript transcript. HFW, AGY contributed to samples collection and transportation. YHD, YL, HXM contributed to laboratory testing. JS, YFN gathered and analyzed the data. All authors read and approved the final manuscript.

\section{Funding}

This work was sponsored by the National Natural Science Foundation of China (No.: 81573204, 81773500) and Henan medical science and technology program (No.: 2018010029, 2018020510).

\section{Availability of data and materials} Not applicable.

\section{Ethics approval and consent to participate}

The research was approved by the Ethical Committee of Henan Center for Disease Control and Prevention, and the committee's reference number is (2016-KY-002-02). Not applicable for consent to participate.

Consent for publication

Not applicable. 


\section{Competing interests}

The authors declare that they have no competing interests.

Received: 27 February 2019 Accepted: 10 June 2019

Published online: 24 June 2019

\section{References}

1. Zhuang L, Sun Y, Cui XM, Tang F, Hu JG, Wang LY, et al. Transmission of severe fever with thrombocytopenia syndrome virus by Haemaphysalis longicornis ticks, China. Emerg Infect Dis. 2018;24:868-71.

2. Li Y, Zhou H, Mu D, Yin W, Yu H. Epidemiological analysis on severe fever with thrombocytopenia syndrome under the national surveillance data from 2011 to 2014, China. Chin J Epidemiol. 2015:36:598-602 (in Chinese).

3. Sun J, Lu L, Wu H, Yang J, Ren J, Liu Q. The changing epidemiological characteristics of severe fever with thrombocytopenia syndrome in China, 2011-2016. Sci Rep. 2017;7(1):9236.

4. Zhan J, Wang Q, Cheng J, Hu B, Li J, Zhan F, et al. Current status of severe fever with thrombocytopenia syndrome in China. Virol Sin. 2017;32(1):51-62

5. Tabara K, Fujita H, Hirata A, Hayasaka D. Investigation of severe fever with thrombocytopenia syndrome virus antibody among domestic bovines transported to slaughterhouse in Shimane prefecture, Japan. Jpn J Infect Dis. 2016:69(5):445-7.

6. Hwang J, Kang JG, Oh SS, Chae JB, Cho YK, Cho YS, et al. Molecular detection of severe fever with thrombocytopenia syndrome virus (SFTSV) in feral cats from Seoul, Korea. Ticks Tick Borne Dis. 2017;8(1):9-12.

7. Chen C, Li P, Li KF, Wang HL, Dai YX, Cheng $X$, et al. Animals as amplification hosts in the spread of severe fever with thrombocytopenia syndrome virus: a systematic review and meta-analysis. Int J Infect Dis. 2019; 79:77-84

8. Yu KM, Yu MA, Park SJ, Kim Yl, Robles NJ, Kwon HI, et al. Seroprevalence and genetic characterization of severe fever with thrombocytopenia syndrome virus in domestic goats in South Korea. Ticks Tick Borne Dis. 2018; 9(5):1202-6.

9. Luo L, Zhao L, Wen H, Zhang Z, Liu J, Fang L, et al. Haemaphysalis longicornis ticks as reservoir and vector of severe fever with thrombocytopenia syndrome virus in China. Emerg Infect Dis. 2015;21(10): 1770-6.

10. Liu K, Zhou H, Sun RX, Yao HW, Li Y, Wang LP, et al. A national assessment of the epidemiology of severe fever with thrombocytopenia syndrome, China. Sci Rep. 2015;23:9679.

11. Huang $X$, Du Y, Hu X, Ma H, Wang H, You A, et al. Epidemiological and etiological characteristics of fever, thrombocytopenia and leukopenia syndrome in Henan Province, China, 2011-2012. PLoS One. 2014;9(3):e91166.

12. Liang S, Bao C, Zhou M, Hu J, Tang F, Guo X, et al. Seroprevalence and risk factors for severe fever with thrombocytopenia syndrome virus infection in Jiangsu Province, China, 2011. Am J Trop Med Hyg. 2014:90(2):256-9.

13. Jiao Y, Zeng X, Guo X, Qi X, Zhang X, Shi Z, et al. Preparation and evaluation of recombinant severe fever with thrombocytopenia syndrome virus nucleocapsid protein for detection of total antibodies in human and animal sera by double-antigen sandwich enzyme-linked immunosorbent assay. J Clin Microbiol. 2012;50(2):372-7.

14. Du YH, Huang XY, Deng WB, Ma HX, Ma H, Man RQ, et al. Culture, isolation and identification of new bunyavirus in African green monkey kidney (Vero) cells. Chin J Prev Med. 2012;46:169-72.

15. Zhang $Y Z$, Zhou DJ, Xiong $Y$, Chen XP, He YW, Sun Q, et al. Hemorrhagic fever caused by a novel tick-borne Bunyavirus in Huaiyangshan, China. Chin J Epidemiol. 2011:32(3):209-20.

16. Tamura K, Dudley J, Nei M, Kumar S. MEGA4: molecular evolutionary genetics analysis (MEGA) software version 4.0. Mol Biol Evol. 2007;24:1596-9.

17. Tian H, Yu P, Chowell G, Li S, Wei J, Tian H, et al. Severe fever with thrombocytopenia syndrome virus in humans, domesticated snimals, ticks, and mosquitoes, Shaanxi Province, China. Am J Trop Med Hyg. 2017;96(6): 1346-9.

18. Gong L, Jiang M, Liu J, Han W, Liu J, Sun Z, et al. Prevalence and homology analysis on human and animals severe fever with thrombocytopenia syndrome virus infection in Yantai of Shandong province. Chin J Epidemiol. 2014;35(5):524-7 in Chinese.

19. Ding $S$, Yin $H, X u X$, Liu G, Jiang S, Wang W, et al. A cross-sectional survey of severe fever with thrombocytopenia syndrome virus infection of domestic animals in Laizhou City, Shandong Province, China. Jpn J Infect Dis. 2014;67(1):1-4.
20. Niu G, Li J, Liang $M$, Jiang $X$, Jiang $M$, Yin $H$, et al. Severe fever with thrombocytopenia syndrome virus among domesticated animals, China. Emerg Infect Dis. 2013;19(5):756-63.

21. Liu JW, Wen HL, Fang LZ, Zhang ZT, He ST, Xue ZF, et al. Prevalence of SFTSV among Asian house shrews and rodents, China, January-august 2013. Emerg Infect Dis. 2014;20(12):2126-8.

22. Li Z, Hu J, Bao C, Li P, Qi X, Qin Y, et al. Seroprevalence of antibodies against SFTS virus infection in farmers and animals, Jiangsu, China. J Clin Virol. 2014;60(3):185-9.

23. Chen XP, Cong ML, Li MH, Kang YJ, Feng YM, Plyusnin A, et al. Infection and pathogenesis of huaiyangshan virus (a novel tick-borne bunyavirus) in laboratory rodents. J Gen Virol. 2012;93(Pt 6:1288-93.

24. Tani H, Fukuma A, Fukushi S, Taniguchi S, Yoshikawa T, Iwata-Yoshikawa N, et al. Efficacy of T-705 (Favipiravir) in the treatment of infections with lethal severe fever with thrombocytopenia syndrome virus. mSphere. 2016;1(1):e00061-15.

25. Liu Y, Wu B, Paessler S, Walker DH, Tesh RB, Yu XJ. The pathogenesis of severe fever with thrombocytopenia syndrome virus infection in alpha/beta interferon knockout mice: insights into the pathologic mechanisms of a new viral hemorrhagic fever. J Virol. 2014;88(3):1781-6.

26. Jin C, Liang M, Ning J, Gu W, Jiang H, Wu W, et al. Pathogenesis of emerging severe fever with thrombocytopenia syndrome virus in C57/BL6 mouse model. Proc Natl Acad Sci U S A. 2012;109(25):10053-8.

27. Jin $C$, Jiang $H$, Liang $M$, Han $Y, G u$ W, Zhang F, et al. SFTS virus infection in nonhuman primates. J Infect Dis. 2015;211(6):915-25.

28. Shimada S, Posadas-Herrera G, Aoki K, Morita K, Hayasaka D. Therapeutic effect of post-exposure treatment with antiserum on severe fever with thrombocytopenia syndrome (SFTS) in a mouse model of SFTS virus infection. Virology. 2015:482:19-27.

29. Matsuno K, Orba Y, Maede-White K, Scott D, Feldmann F, Liang M, et al. Animal models of emerging tick-borne phleboviruses: determining target cells in a lethal model of SFTSV infection. Front Microbiol. 2017:8:104.

30. Jiao Y, Qi X, Liu D, Zeng X, Han Y, Guo X, et al. Experimental and natural infections of goats with severe fever with thrombocytopenia syndrome virus: evidence for ticks as viral vector. PLoS Negl Trop Dis. 2015;9(10):e0004092.

Ready to submit your research? Choose BMC and benefit from:

- fast, convenient online submission

- thorough peer review by experienced researchers in your field

- rapid publication on acceptance

- support for research data, including large and complex data types

- gold Open Access which fosters wider collaboration and increased citations

- maximum visibility for your research: over $100 \mathrm{M}$ website views per year

At $\mathrm{BMC}$, research is always in progress.

Learn more biomedcentral.com/submission 